\title{
Is routine extubation overnight safe in cardiac surgery patients?
}

Elizabeth D. Krebs, MD, MSc, ${ }^{\mathrm{a}}$ Robert B. Hawkins, MD, MSc, ${ }^{\mathrm{a}}$ J. Hunter Mehaffey, MD, MSc, ${ }^{\mathrm{a}}$ Clifford E. Fonner, BA, ${ }^{b}$ Alan M. Speir, MD, ${ }^{\mathrm{c}}$ Mohammed A. Quader, MD, ${ }^{\mathrm{d}}$ Jeffrey B. Rich, MD, Leora T. Yarboro, MD, ${ }^{\mathrm{a}}$ Nicholas R. Teman, MD, ${ }^{\mathrm{a}}$ and Gorav Ailawadi, MD ${ }^{\mathrm{a}}$

\section{ABSTRACT}

Objectives: Expedient extubation after cardiac surgery has been associated with improved outcomes, leading to postoperative extubation frequently during overnight hours. However, recent evidence in a mixed medical-surgical intensive care unit population demonstrated worse outcomes with overnight extubation. This study investigated the impact of overnight extubation in a statewide, multicenter Society of Thoracic Surgeons database.

Methods: Records from 39,812 patients undergoing coronary artery bypass grafting or valve operations (2008-2016) and extubated within 24 hours were stratified according to extubation time between 06:00 and 18:00 (day) or between 18:00 and 6:00 (overnight). Outcomes including reintubation, mortality, and composite morbidity-mortality were evaluated using hierarchical regression models adjusted for Society of Thoracic Surgeons predictive risk scores. To further analyze extubation during the night, a subanalysis stratified patients into 3 groups: 06:00 to 18:00, 18:00 to $24: 00$, and 24:00 to $06: 00$.

Results: A total of 20,758 patients were extubated overnight $(52.1 \%)$ and were slightly older (median age 66 vs 65 years, $P<.001$ ) with a longer duration of ventilation ( 4 vs 7 hours, $P<.001$ ). Day and overnight extubation were associated with equivalent operative mortality $(1.7 \%$ vs $1.7 \%, P=.880)$, reintubation (3.7\% vs $3.4 \%, P=.141)$, and composite morbidity-mortality $(8.2 \%$ vs $8.0 \%$, $P=.314)$. After risk adjustment, overnight extubation was not associated with any difference in reintubation, mortality, or composite morbidity-mortality. On subanalysis, those extubated between 24:00 and 06:00 exhibited increased composite morbidity-mortality (odds ratio, $1.18 ; P=.001$ ) but no difference in reintubation or mortality.

Conclusions: Extubation overnight was not associated with increased mortality or reintubation. These results suggest that in the appropriate clinical setting, it is safe to routinely extubate cardiac surgery patients overnight. ( $\mathrm{J}$ Thorac Cardiovasc Surg 2019;157:1533-42)

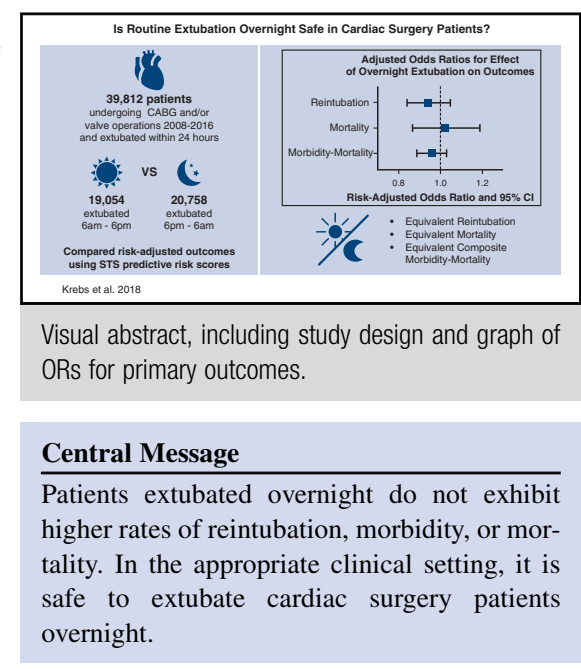

Perspective

Extubation as soon as feasible has been associated with improved outcomes in cardiac surgery patients. However, recent data have associated extubation overnight with increased mortality and rates of reintubation. We sought to determine the safety of overnight extubation in a regional consortium of cardiac surgery centers.

See Commentary on page 1543.

\footnotetext{
From the ${ }^{\mathrm{a} D i v i s i o n}$ of Thoracic and Cardiovascular Surgery, University of Virginia, Charlottesville, Va; ${ }^{\mathrm{b}}$ Virginia Cardiac Services Quality Initiative, Virginia Beach, Va; ${ }^{\mathrm{c} I N O V A}$ Heart and Vascular Institute, Falls Church, Va; ${ }^{\mathrm{d}}$ Division of Cardiothoracic Surgery, Virginia Commonwealth University, Richmond, Va; and ${ }^{\mathrm{e}} \mathrm{Heart}$ and Vascular Institute, Cleveland Clinic, Cleveland, Ohio.

The National Institutes of Health supported research in this publication under award numbers T32 HL007849 (J.H.M., R.B.H.) and UM1 HL088925 (E.D.K.).

Read at the 98th Annual Meeting of The American Association for Thoracic Surgery, San Diego, California, April 28-May 1, 2018.

Received for publication Feb 5, 2018; revisions received Aug 21, 2018; accepted for publication Aug 25, 2018; available ahead of print Dec 18, 2018.

Address for reprints: Gorav Ailawadi, MD, Division of Cardiovascular Surgery, Department Surgery, PO Box 800679, Charlottesville, VA 22908-0709 (E-mail: ga3f@virginia.edu).

$0022-5223 / \$ 36.00$

Copyright (c) 2018 by The American Association for Thoracic Surgery

https://doi.org/10.1016/j.jtcvs.2018.08.125
}

Prolonged duration of mechanical ventilation is associated with inferior outcomes in patients who have undergone cardiac surgery, affecting morbidity, cost, length of stay, ventilator-associated pneumonia, and risk-adjusted allcause mortality. ${ }^{1-6}$ Efforts to promote early extubation have included a shift to short-acting, opioid-reducing

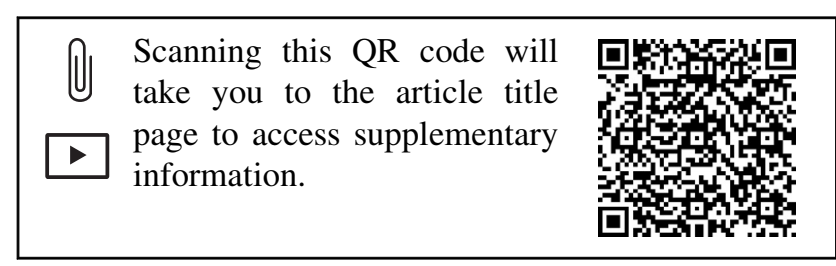




$$
\begin{aligned}
& \text { Abbreviations and Acronyms } \\
& \mathrm{CABG}=\text { coronary artery bypass grafting } \\
& \text { ICU = intensive care unit } \\
& \mathrm{OR}=\text { odds ratio } \\
& \text { PROM }=\text { predicted risk of mortality } \\
& \text { STS = Society of Thoracic Surgeons } \\
& \text { VCSQI }=\text { Virginia Cardiac Services Quality } \\
& \text { Initiative }
\end{aligned}
$$

anesthetic techniques, implementation of early ventilator weaning protocols, and the recognition of extubation within 6 and 24 hours as important quality metrics. ${ }^{7-12}$ These initiatives have driven extubation at all times of the day, including overnight, when there are often limited resources available. However, recent research has suggested that patients extubated overnight have worse outcomes, with increased risk for reintubation and higher rates of intensive care unit (ICU) and in-hospital mortality in a mixed medical-surgical ICU population. ${ }^{13}$ It is unclear if these results are translatable to patients who have undergone cardiac surgery, who often have shorter durations of intubation than patients in the medical ICU. A separate, smaller study containing a large proportion of patients admitted after cardiac surgery found no difference in outcomes between day and night extubations. ${ }^{14}$ In addition, 24-hour intensivist coverage in cardiothoracic surgery ICUs has been demonstrated to be associated with improved outcomes, indicating that continuation of daytime practices to the night may be beneficial in these patients. ${ }^{15,16}$

The outcomes of overnight extubation are especially relevant in the cardiac surgery population, in whom the risks of extubating patients overnight compared with the wellstudied benefits of early extubation carry important implications for intensivist staffing, quality metric reporting, and reduction in healthcare-associated costs. However, this has not been well studied in a uniquely cardiac surgery population. This study aimed to compare risk-adjusted outcomes between patients extubated during the day and overnight, specifically looking at rates of reintubation, mortality, morbidity, length of stay, and cost. We hypothesized that patients extubated overnight would be at increased risk for adverse outcomes because of lack of resources during this time period across a wide range of institutions.

\section{MATERIALS AND METHODS \\ Patient Data}

This study represents a retrospective review of prospectively collected data from the multi-institutional Virginia Cardiac Services Quality Initiative (VCSQI) database. The VCSQI is a voluntary consortium of 19 cardiac surgery practices in Virginia and North Carolina. The collaborative pools standard Society of Thoracic Surgeons (STS) clinical data, which are subsequently matched with cost data, as previously described. ${ }^{17}$ Clinical data are collected separately by member institutions using standard STS definitions and data abstraction practices. ${ }^{18}$ The combined data are devoid of patient and institutional identifiers, and thus the study was exempt from University of Virginia Institutional Review Board.

Data from all patients with an STS predicted risk score undergoing coronary artery bypass grafting (CABG), valve surgery (including aortic valve replacement, mitral valve replacement, and mitral valve repair), or combination of CABG and valve surgery between 2008 and 2016 were selected. Patients extubated in the operating room and patients intubated for greater than 24 hours were excluded. These patients were selected to represent common cardiac surgery operations and to exclude patients with a prolonged ventilatory course. Intubation data, including time of initial extubation, duration of intubation, and need for reintubation, are standardly collected with STS data. Standard STS definitions of operative mortality (composite deaths during hospitalization and within 30 days from surgery) and major morbidity (renal failure, prolonged ventilation, stroke, reoperation, and deep sternal wound infection) were used. ${ }^{19}$ STS scores for predicted risk of mortality (PROM), predicted risk of mortality or morbidity, predicted risk of prolonged mechanical ventilation, and predicted risk of prolonged hospital stay were abstracted for risk adjustment.

Primary outcomes were mortality, composite STS major morbidity or mortality, and need for reintubation during hospitalization. Secondary outcomes included hospital and ICU length of stay, hospital cost, and major morbidities, including postoperative kidney injury, stroke, sternal wound infection, and need for reoperation. Although prolonged ventilation greater than 24 hours is also a major morbidity, these patients were largely excluded from the study because of our inclusion criteria of extubation with 24 hours. Study outcomes and data comparisons were established a priori.

\section{Statistical Analysis}

Patients were stratified into 2 groups by time of initial extubation: 06:00 to 18:00 (day) and 18:00 to 06:00 (night) for the primary analysis. These times were chosen because they are similar to times chosen in existing studies of overnight extubation and reflect common changeover times of ICU physicians, nurses, and respiratory therapists. ${ }^{13,14,20}$ To account for afternoon cardiac cases and to further investigate patients extubated later in the night, a subanalysis was performed, separating patients into 3 groups by extubation time of 06:00 to $18: 00,18: 00$ to $24: 00$, and 24:00 to $06: 00$. Outcomes were compared using both univariate analysis and multivariable regression to estimate risk-adjusted association measures. Univariate statistics included Wilcoxon rank-sum and Kruskal-Wallis tests for continuous variables and chi-square for categoric variables. Hierarchical generalized linear mixed models were created, controlling for preoperative risk by incorporating STS predictive risk scores appropriate for each variable into the hierarchical model and controlling for center-specific variability as a random effect in the model. Rate of reintubation was risk adjusted using STS predicted prolonged ventilation as a composite metric of preoperative pulmonary risk. Mortality measures were risk adjusted using STS-PROM in the multivariable model, and rate of composite morbidity and mortality and cost data were risk-adjusted using risk of morbidity or mortality metric (predicted risk of mortality or morbidity). Length of stay was risk adjusted using STS predicted prolonged hospital stay, as was length of ICU stay. A sensitivity analysis was also performed, including additional variables into the hierarchical models for both the 2 -group and 3-group comparison. In this sensitivity analysis, the cardiopulmonary bypass time was included in the analysis as a surrogate for operative complexity, and "early extubation" or extubation within 6 hours was included as a marker of ventilatory complexity. The effect of extubation at any hour of the day on reintubation and mortality was further analyzed graphically by separating patients into 2-hour blocks by time of extubation. A hierarchical regression analyzed the odds of reintubation or mortality in each of these time categories, while controlling for preoperative risk scores. Statistical analysis was performed using SAS Version 9.4 (SAS Institute, Inc, Cary, NC). 


\section{RESULTS}

\section{Patient Characteristics}

A total of 41,993 patients were included in the study who underwent $\mathrm{CABG}$, valve surgery, or $\mathrm{CABG}$ plus valve operations between 2008 and 2016. Of these patients, 669 were excluded because of extubation in the operating room, 202 were excluded because of missing extubation time, and 2181 were excluded because of initial extubation more than 24 hours after surgery. A total of 39,812 patients met inclusion criteria: Of these, 19,054 patients (47.9\%) were extubated during the day (06:00-18:00) and 20,758 patients $(52.1 \%)$ were extubated at night (18:00-06:00). Demographics, comorbidities, and operative details for the 2 groups are shown in Table 1 . Patients extubated at night were more likely to be female $(29.6 \%$ vs $28.0 \%$, $P=.001)$ and had a higher median age (66 vs 65 years, $P<.001)$. There were also incremental but statistically significant differences in preoperative risk scores, comorbidity profiles, type of operation, and urgency of the cases (Table 1).

\section{Univariate Analysis}

Patients extubated overnight did not experience higher reintubation rates $(3.7 \%$ vs $3.4 \%, 0.141)$. There were also no differences in operative mortality $(1.7 \%$ vs $1.7 \%, P=.88)$ or composite morbidity-mortality $(8.2 \%$ vs $8.0 \%, P=.11$ ) between the 2 groups. A greater proportion of patients extubating in the day extubated within 6 hours $(68.7 \%$ vs $38.4 \%, P<.001)$, and patients extubated during the day had a shorter initial duration of mechanical ventilation (median time 4 vs 7 hours, $P<.001)$. Patients extubated during the day exhibited a shorter postoperative length of stay (5 vs 6 days, $P<.001$ ) but a marginally longer ICU length of stay (46 vs 45 hours, $P<.001)$. Patients extubated during the day also exhibited a decreased total hospital cost than those extubated overnight $(\$ 35,670$ vs $\$ 37,840, P<.001)$. Patients who were reintubated during the hospital stay had a higher rate of operative mortality $(22.8 \%$ vs $0.92 \%, P<.0001)$ and higher rate of composite morbidity and mortality $(93.7 \%$ vs $5.0 \%, P<.001)$. Univariate outcomes are shown in Table 2.

\section{Risk-Adjusted Analysis}

Because patients extubated overnight had important clinical differences, risk adjustment was performed using STS predictive risk scores. After adjustment, overnight extubation was not associated with higher reintubation rate (adjusted odds ratio [OR], 0.94; $P=.25$ ), mortality (adjusted OR, 1.013; $P=.87$ ), or composite morbidity and mortality (adjusted OR, $0.95 ; P=.23$ ). Patients extubated overnight did exhibit a shorter risk-adjusted ICU length of stay (effect -4.5 hours, $P<.001$ ). Risk-adjusted outcome measures are shown in Table 3 with full models in Table E1.

\section{Subgroup Analysis: Three Time Periods}

To further analyze patients extubated later in the night, a subgroup analysis separated patients into those extubated earlier or later in the night. Specifically, 19,054 patients $(47.9 \%)$ were extubated between 06:00 and 18:00, 14,666 patients $(36.8 \%)$ were extubated between 18:00 and $24: 00$, and 6092 patients $(15.3 \%)$ were extubated between 24:00 and 06:00. There were small yet statistically significant differences in comorbidities and type of surgery between groups (Table 4). Patients extubated between 24:00 and 06:00 exhibited the greatest preoperative risk scores, including PROM of $1.5 \%$ compared with $1.1 \%$ in the 06:00 to $18: 00$ group and $1.2 \%$ in the $18: 00$ to $24: 00$ group $(P<.001)$. On univariate analysis, there was a statistically significant difference in unadjusted reintubation rates between the groups, with those extubated from 18:00 to 24:00 exhibiting the lowest rate of reintubation and those extubated from 24:00 to 06:00 exhibiting the highest rate of reintubation $(3.7 \%$ vs $3.2 \%$ vs $3.9 \%, P=.006)$. There was no difference in operative mortality on univariate analysis $(P=.345)$. There was a difference in composite morbidity-mortality among the 3 groups, with 18:00 to 24:00 exhibiting the lowest rate of composite morbidity and 24:00 to 06:00 exhibiting the highest rate of composite morbidity $(8.2 \%$ vs $6.9 \%$ vs $10.5 \%, P<.001)$. Demographics and outcomes are shown in Table 4.

After risk adjustment using multivariable hierarchical logistic regression models, neither extubation from 18:00 to 24:00 nor extubation from 24:00 to 06:00 affected reintubation or mortality rates (all $P>.05$ ). However, extubation between 18:00 and 24:00 was associated with slightly decreased composite morbidity and mortality (OR, 0.856; $P<.001$ ), whereas extubation between 24:00 and 06:00 was associated with an increase in composite morbidity and mortality (OR, 1.180; $P=.001$.) Risk-adjusted outcome measures are shown in Table 5 with full models in Table E2.

\section{Sensitivity Analyses}

A sensitivity analysis further risk adjusted primary outcomes by controlling for cardiopulmonary bypass time (as a surrogate for operative complexity) and whether or not the patient was extubated within 6 hours, in addition to preoperative risk scores. In this analysis, extubation overnight was associated with reduced risk of reintubation (OR, $0.812 ; P<.001$ ), operative mortality (OR, 0.843; $P=.049$ ), and composite morbidity and mortality (OR, $0.790 ; P<.001)$. When further separating the night time period, extubation from 18:00 to 24:00 and from 24:00 to 06:00 were both associated with equivalent or reduced rates of reintubation, operative mortality, and morbidity or 
TABLE 1. Patient demographics and operative characteristics of patients extubated during the day (06:00-18:00) versus at night (18:00-06:00)

\begin{tabular}{|c|c|c|c|}
\hline Variable & $\begin{array}{l}\text { Day extubation } \\
(\mathrm{n}=1 \mathbf{1 9 0 5 4})\end{array}$ & $\begin{array}{l}\text { Night extubation } \\
\qquad(\mathrm{n}=\mathbf{2 0 7 5 8})\end{array}$ & $\begin{array}{c}P \\
\text { value }\end{array}$ \\
\hline Age (y) & 65 [57-73] & $66[58-74]$ & $<.001$ \\
\hline Sex (male) & $72.0 \%$ & $70.4 \%$ & .001 \\
\hline Smoker & $30.6 \%$ & $27.8 \%$ & $<.001$ \\
\hline Hypertension & $83.0 \%$ & $84.4 \%$ & $<.001$ \\
\hline Diabetes & $39.7 \%$ & $41.7 \%$ & $<.001$ \\
\hline PAD & $12.3 \%$ & $12.9 \%$ & .072 \\
\hline Dialysis & $2.4 \%$ & $2.7 \%$ & .166 \\
\hline CVD & $15.9 \%$ & $17.1 \%$ & .001 \\
\hline Prior CVA & $6.2 \%$ & $6.6 \%$ & .100 \\
\hline Prior MI & $41.2 \%$ & $42.4 \%$ & .015 \\
\hline Endocarditis & $1.7 \%$ & $1.6 \%$ & .386 \\
\hline $\begin{array}{l}\text { NYHA class } \\
\text { I } \\
\text { II } \\
\text { III } \\
\text { IV }\end{array}$ & $\begin{array}{r}6.5 \% \\
35.5 \% \\
40.2 \% \\
17.8 \%\end{array}$ & $\begin{array}{r}6.7 \% \\
35.6 \% \\
40.2 \% \\
17.6 \%\end{array}$ & .963 \\
\hline Preoperative EF $(\%)$ & 55 [45-60] & $55[45-60]$ & .316 \\
\hline Procedure type & & & $<.001 *$ \\
\hline AVR & $12.3 \%$ & $11.3 \%$ & \\
\hline $\mathrm{AVR}+\mathrm{CABG}$ & $6.5 \%$ & $8.4 \%$ & \\
\hline CABG & $72.1 \%$ & $71.9 \%$ & \\
\hline MV repair & $4.4 \%$ & $3.2 \%$ & \\
\hline $\begin{array}{l}\text { MV repair }+ \\
\text { CABG }\end{array}$ & $1.6 \%$ & $2.1 \%$ & \\
\hline $\begin{array}{l}\text { MV replace + } \\
\text { CABG }\end{array}$ & $0.7 \%$ & $0.9 \%$ & \\
\hline MV replace & $2.3 \%$ & $2.2 \%$ & \\
\hline Urgency & & & $<.001 *$ \\
\hline Elective & $48.9 \%$ & $45.9 \%$ & \\
\hline Urgent & $48.6 \%$ & $52.0 \%$ & \\
\hline Emergent & $2.6 \%$ & $2.0 \%$ & \\
\hline Salvage & $0.04 \%$ & $0.04 \%$ & \\
\hline Reoperation & $4.4 \%$ & $5.6 \%$ & $<.001$ \\
\hline Previous PCI & $80.5 \%$ & $78.5 \%$ & .008 \\
\hline $\begin{array}{l}\text { Crossclamp } \\
\quad \text { time (min) }\end{array}$ & 70 [53-90] & 74 [57-95] & $<.001$ \\
\hline $\begin{array}{l}\text { Bypass } \\
\text { time (min) }\end{array}$ & 95 [75-120] & 101 [75-130] & $<.001$ \\
\hline OR exit time & $12: 45$ [11:52-14:10] & $14: 40$ [13:09-16:52] & $<.001$ \\
\hline STS PROM (\%) & $1.1[0.6-2.4]$ & $1.3[0.6-2.6]$ & $<.001$ \\
\hline STS PROMM (\%) & 11.9 [7.9-19.5] & $12.9[5.1-13.8]$ & $<.001$ \\
\hline
\end{tabular}

TABLE 1. Continued

\begin{tabular}{|c|c|c|c|}
\hline Vari & $(n=19054)$ & $\begin{array}{l}\text { ight extubation } \\
(n=20758)\end{array}$ & $\begin{array}{c}P \\
\text { value }\end{array}$ \\
\hline vent $(\%)$ & & 8. & 1 \\
\hline $\begin{array}{l}\text { TS predicted } \\
\text { long LOS }(\%)\end{array}$ & 4.2 & 4.6 & $<.001$ \\
\hline \multicolumn{4}{|c|}{$\begin{array}{l}\text { sults reported as percentage or median [25th-75th percentile]. } P A D \text {, Peripheral } \\
\text { cular disease; } C V D \text {, cerebrovascular disease; } C V A \text {, cerebrovascular accident; } \\
\text {, myocardial infarction; } N Y H A, \text { New York Heart Association; } E F \text {, ejection fraction; } \\
R \text {, aortic valve replacement; } C A B G \text {, coronary artery bypass grafting; } M V \text {, mitral } \\
\text { ve; } P C I \text {, percutaneous coronary intervention; } O R \text {, operating room; } S T S \text {, Society } \\
\text { Thoracic Surgeons; } P R O M \text {, predicted risk of mortality; } P R O M M \text {, predicted risk } \\
\text { morbidity or mortality; long vent, mechanical ventilation greater than } 24 \text { hours; }\end{array}$} \\
\hline
\end{tabular}

mortality. (Results and full models are shown in the Tables E3, E4, and E5.)

A graphical representation of adjusted ORs for reintubation and mortality by hour of extubation is shown in Figure 1. The full models are shown in Tables E6 and E7. Further discussion and description of results can be seen in Video 1.

\section{DISCUSSION}

This study represents a novel investigation of overnight extubation in a cohort of approximately 40,000 patients undergoing cardiac surgery. Approximately half of patients undergoing routine cardiac surgery were extubated overnight. Contrary to our hypothesis, extubation overnight was not associated with increased risk-adjusted need for reintubation, mortality, or major complications. When further separating the overnight time periods into groups of 18:00 to $24: 00$ and $24: 00$ to $06: 00$, there was a slightly decreased rate of composite morbidity-mortality in the group extubated from 18:00 to 24:00 and a slightly increased rate of composite morbidity-mortality in the group extubated from 24:00 to 06:00. However, there remained no differences in risk-adjusted reintubation rates or risk-adjusted mortality among the 3 groups. When further controlling for bypass time and early extubation (within 6 hours) in a sensitivity analysis, all overnight time periods were associated with equivalent or reduced rates of reintubation, mortality, and composite morbidity-mortality compared with extubation during the day.

These findings contrast the largest existing study of overnight extubation, conducted by Gershengorn and colleauges, ${ }^{13}$ in a multicenter cohort of 97,844 mixed medical and surgical patients. This study found increased risk of reintubation, ICU mortality, and in-hospital 
TABLE 2. Unadjusted outcomes in patients extubated during the day (06:00-18:00) versus at night (18:00-06:00)

\begin{tabular}{|c|c|c|c|}
\hline Outcome & Day extubation $(n=19054)$ & Night extubation $(n=20758)$ & $P$ value \\
\hline Initial hours ventilated & $4[3-14]$ & 7 [5-9] & $<.001$ \\
\hline Postoperative LOS (d) & 5 [4-7] & 6 [4-7] & $<.001$ \\
\hline ICU length of stay (h) & $46[25-72]$ & 45 [24-72] & $<.001$ \\
\hline Extubated within $6 \mathrm{~h}$ & $68.7 \%$ & $38.4 \%$ & $<.001$ \\
\hline Reintubation & $3.7 \%$ & $3.4 \%$ & .141 \\
\hline Cardiac arrest & $1.1 \%$ & $1.2 \%$ & .731 \\
\hline Deep sternal wound infection & $0.2 \%$ & $0.2 \%$ & .544 \\
\hline Pneumonia & $1.7 \%$ & $1.5 \%$ & .155 \\
\hline Renal failure & $2.2 \%$ & $2.4 \%$ & .254 \\
\hline Reoperation & $3.1 \%$ & $2.7 \%$ & .026 \\
\hline Stroke & $1.1 \%$ & $1.0 \%$ & .600 \\
\hline STS major morbidity & $7.4 \%$ & $7.0 \%$ & .111 \\
\hline 30-d mortality & $1.3 \%$ & $1.4 \%$ & .837 \\
\hline Composite morbidity-mortality & $8.2 \%$ & $8.0 \%$ & .314 \\
\hline Operative mortality & $1.7 \%$ & $1.7 \%$ & .880 \\
\hline Total cost & $\$ 35,670[\$ 28,240-\$ 48,160]$ & $\$ 37,840[\$ 30,400-\$ 49,950]$ & $<.001$ \\
\hline Total ICU cost & $\$ 6360$ [\$2840-\$9890] & $\$ 6640[\$ 4130-\$ 10,250]$ & $<.001$ \\
\hline
\end{tabular}

Results reported as percentage or median [25th-75th percentile]. LOS, Length of stay; ICU, intensive care unit; STS, Society of Thoracic Surgeons.

mortality in those extubated at night. ${ }^{13}$ However, only 4 $(2.5 \%)$ of the 165 ICUs in their study represent cardiac surgery ICUs. ${ }^{13}$ These medical and general surgical ICUs likely contained patients intubated for a relatively longer period of time compared with patients in the cardiac ICU, who are primarily intubated for surgery and extubated in the following 24 to 48 hours. Moreover, in their population, only one-fifth of patients were extubated overnight, whereas approximately half of our patient population extubated overnight. Although their study did not analyze cardiac surgery patients separately, subgroup analyses of surgical patients alone did not find detrimental outcomes. ${ }^{13}$ A similar but smaller study in a mixed population of 2240 ICU patients, half of whom were postoperative cardiac surgery patients, did not demonstrate worse outcomes in patients extubated overnight. ${ }^{14}$ Furthermore, in a subgroup of only

TABLE 3. Risk-adjusted association measures for effect of extubation overnight (18:00-06:00) on outcomes

\begin{tabular}{lccc}
\hline Logistic regression & OR & $\mathbf{9 5} \%$ CI & $\boldsymbol{P}$ value \\
\hline Reintubation & 0.937 & $0.840-1.046$ & .245 \\
Operative mortality & 1.013 & $0.865-1.188$ & .871 \\
Morbidity or mortality & 0.954 & $0.886-1.029$ & .225 \\
\hline Linear regression & Effect & $\mathbf{9 5} \%$ CI & $\boldsymbol{P}$ value \\
\hline ICU LOS & -4.509 & -6.238 to -2.980 & $<.001$ \\
Postsurgery LOS & -0.020 & -0.123 to -0.83 & .707 \\
Total cost & $-\$ 144$ & $-\$ 660-\$ 372$ & .585 \\
\hline$O R, O d$
\end{tabular}

$O R$, Odds ratio; $C I$, confidence interval; $I C U$, intensive care unit; $L O S$, length of stay. cardiac surgery ICU patients, that study reported decreased reintubation and mortality for patients extubated at night, consistent with our results. ${ }^{14}$ Collectively, these studies suggest that although overnight extubation has been associated with worsened outcomes in mixed ICU populations, routine cardiac surgery patients do not necessarily exhibit these same detrimental outcomes.

Patients in our study who extubated overnight exhibited a longer median ventilation time than those extubated during the day. A greater proportion of patients extubated during the day were extubated within 6 hours of surgery. This was especially notable in the subgroup analysis, in which $68.8 \%$ of patients extubated in the day extubated within 6 hours of surgery, compared with $50.2 \%$ between 18:00 and 24:00 and only 9.7\% between 24:00 and 06:00. These differences were expected, given that most elective patients exit the operating room in the afternoon or evening; thus, patients extubated overnight more likely consisted of patients unable to extubate during the day or patients whose cases ended later in the day. Although STS quality metric reporting records early extubation as less than 6 hours and prolonged ventilation as greater than 24 hours, the exact inflection point at which increased extubation time affects outcomes remains a subject of investigation. ${ }^{3,10,21}$ Extubation within 9 or 12 hours after operation has been suggested as a potential threshold of worsened outcomes, although improved outcomes have been shown at a variety of early extubation time points. ${ }^{1-3,21}$ Time points of 9 to 12 hours after the operating room often occur overnight, highlighting the relevance of data on extubation in this time period. 
TABLE 4. Selected demographics and unadjusted outcomes for 3-group analysis

\begin{tabular}{|c|c|c|c|c|}
\hline Variable & $\begin{array}{c}\text { Extubation } \\
\text { 06:00-18:00 }(n=19054)\end{array}$ & $\begin{array}{c}\text { Extubation } \\
\text { 18:00-24:00 }(n=14666)\end{array}$ & $\begin{array}{c}\text { Extubation } \\
\text { 24:00-06:00 }(n=6092)\end{array}$ & $P$ value \\
\hline Age (y) & 65 [57-73] & 65 [57-73] & $67[59-74]$ & $<.001$ \\
\hline Sex (male) & $72.0 \%$ & $71.9 \%$ & $66.9 \%$ & $<.001$ \\
\hline Smoker & $30.6 \%$ & $28.8 \%$ & $25.5 \%$ & $<.001$ \\
\hline Diabetes & $39.7 \%$ & $41.1 \%$ & $43.0 \%$ & $<.001$ \\
\hline Heart failure & $23.8 \%$ & $23.2 \%$ & $26.8 \%$ & $<.001$ \\
\hline Preoperative EF (\%) & $55[45-60]$ & $55[45-60]$ & $55[45-60]$ & .003 \\
\hline $\begin{array}{l}\text { Procedure type } \\
\text { AVR } \\
\text { AVR }+ \text { CABG } \\
\text { CABG } \\
\text { MV repair } \\
\text { MV repair + CABG } \\
\text { MV replace }+ \text { CABG } \\
\text { MV replace }\end{array}$ & $\begin{array}{r}12.3 \% \\
6.5 \% \\
72.1 \% \\
4.4 \% \\
1.6 \% \\
0.7 \% \\
2.3 \%\end{array}$ & $\begin{array}{r}11.6 \% \\
7.9 \% \\
72.1 \% \\
3.7 \% \\
1.8 \% \\
0.8 \% \\
2.2 \%\end{array}$ & $\begin{array}{r}10.4 \% \\
9.9 \% \\
71.2 \% \\
2.2 \% \\
2.7 \% \\
1.3 \% \\
2.3 \%\end{array}$ & $<.001$ \\
\hline OR exit time & $12: 45[11: 52-14: 10]$ & $14: 15$ [12:58-16:08] & $16: 25[13: 50-18: 21]$ & $<.001$ \\
\hline STS PROM (\%) & $1.1[0.6-2.4]$ & $1.2[0.6-2.4]$ & $1.5[0.7-3.2]$ & $<.001$ \\
\hline STS PROMM (\%) & 11.9 [7.9-19.5] & $11.0[8.3-19.3]$ & $14.5[9.2-23.6]$ & $<.001$ \\
\hline STS predicted long vent $(\%)$ & $7.4[4.7-12.9]$ & $7.8[4.9-12.8]$ & $9.3[5.7-16.2]$ & $<.001$ \\
\hline STS predicted long LOS $(\%)$ & $4.2[3.0-6.3]$ & $5.6[2.5-8.1]$ & $5.4[2.9-10.3]$ & $<.001$ \\
\hline \multicolumn{5}{|l|}{ Outcome } \\
\hline Initial hours ventilated & $4[3-14]$ & $6[5-8]$ & $10[8-13]$ & $<.001$ \\
\hline Postoperative LOS (d) & $5[4-7]$ & $5[4-7]$ & $6[5-8]$ & $<.001$ \\
\hline ICU length of stay (h) & $46[25-72]$ & $44[24-70]$ & $54[25-79]$ & $<.001$ \\
\hline Extubated within $6 \mathrm{~h}$ & $68.7 \%$ & $50.3 \%$ & $9.7 \%$ & $<.001$ \\
\hline Reintubation & $3.7 \%$ & $3.2 \%$ & $3.9 \%$ & .006 \\
\hline Deep sternal wound infection & $0.2 \%$ & $0.2 \%$ & $0.3 \%$ & .346 \\
\hline Pneumonia & $1.7 \%$ & $1.4 \%$ & $1.8 \%$ & .034 \\
\hline Renal failure & $2.2 \%$ & $2.1 \%$ & $3.3 \%$ & $<.001$ \\
\hline Reoperation & $3.1 \%$ & $2.2 \%$ & $4.1 \%$ & $<.001$ \\
\hline Stroke & $1.1 \%$ & $0.9 \%$ & $1.3 \%$ & .009 \\
\hline STS major morbidity & $7.4 \%$ & $6.0 \%$ & $9.6 \%$ & $<.001$ \\
\hline Composite morbidity-mortality & $8.2 \%$ & $6.9 \%$ & $10.5 \%$ & $<.001$ \\
\hline Operative mortality & $1.7 \%$ & $1.6 \%$ & $1.9 \%$ & .345 \\
\hline Total cost & $\$ 35,670[\$ 28,240-\$ 48,160]$ & $\$ 36,560[\$ 29,650-\$ 47,300]$ & $\$ 41,820[\$ 32,960-\$ 57,360]$ & $<.001$ \\
\hline Total ICU cost & $\$ 6360[\$ 2840-\$ 9890]$ & $\$ 6520[\$ 4160-\$ 10,070]$ & $\$ 6850[\$ 3940-\$ 10,780]$ & $<.001$ \\
\hline
\end{tabular}

Results reported as percentage or median [25th-75th percentile]. $E F$, Ejection fraction; $A V R$, aortic valve replacement; $C A B G$, coronary artery bypass grafting; $M V$, mitral valve; $O R$, operating room; STS, Society of Thoracic Surgeons; PROM, predicted risk of mortality; PROMM, predicted risk of morbidity or mortality; long vent, mechanical ventilation more than 24 hours; $L O S$, length of stay; $I C U$, intensive care unit.

Although none of the groups exhibited differences in risk-adjusted reintubation or operative mortality, it is notable that patients extubated between 24:00 and 06:00 did exhibit increased risk-adjusted composite morbidity-mortality. This group exhibited marginally increased rates of the major comorbidities of stroke, renal failure, and reoperation, but it is unclear what role extubation during this time period plays in the increase in morbidity. This group tended to be sicker at baseline and with older age, higher STS preoperative risk scores, and a longer median ventilation time than the other 2 groups of patients, as well as more complex operative procedures (including CABG/valve procedures) and longer cardiopulmonary bypass and crossclamp time. These differences also may account for this difference in composite morbidity and mortality. Notably, when controlling for cardiopulmonary bypass time (as an additional surrogate for operative complexity) and early extubation (within 6 hours) in a sensitivity analysis, extubation between 24:00 and 06:00 was actually associated with a decrease rather than an increase in composite morbidity-mortality. 
TABLE 5. Risk-adjusted outcomes for 3-group analysis

\begin{tabular}{lccc}
\hline \multicolumn{1}{c}{ Logistic regression } & OR & $\mathbf{9 5} \% \mathbf{C I}$ & $\boldsymbol{P}$ value \\
\hline $\begin{array}{l}\text { Reintubated during hospital } \\
\quad \text { stay }\end{array}$ & & & \\
18:00-24:00 & 0.91 & $0.802-1.025$ & .116 \\
24:00-06:00 & 1.00 & $0.860-1.172$ & .961 \\
Operative mortality & & & \\
18:00-24:00 & 1.017 & $0.854-1.212$ & .844 \\
24:00-06:00 & 1.004 & $0.803-1.258$ & .974 \\
Morbidity or mortality & & & \\
18:00-24:00 & 0.856 & $0.786-0.932$ & $<.001$ \\
24:00-06:00 & 1.180 & $1.066-1.307$ & .001 \\
\hline
\end{tabular}

In our population, extubation overnight was not associated with a decrease in overall length of stay or hospital cost. Patients extubated overnight exhibited a median length of stay 1 day greater than those extubated during the day, despite a marginally decreased ICU length of stay. However, it is notable that patients extubated in the night had later operating room exit times, and this increase in overall stay may be from an extra overnight stay due to a later ICU arrival time rather than complications. Patients in the night group had slightly decreased risk-adjusted ICU length of stay, although this could also be because these patients more likely arrived to the ICU later in the day than those extubated in the daytime, contributing to
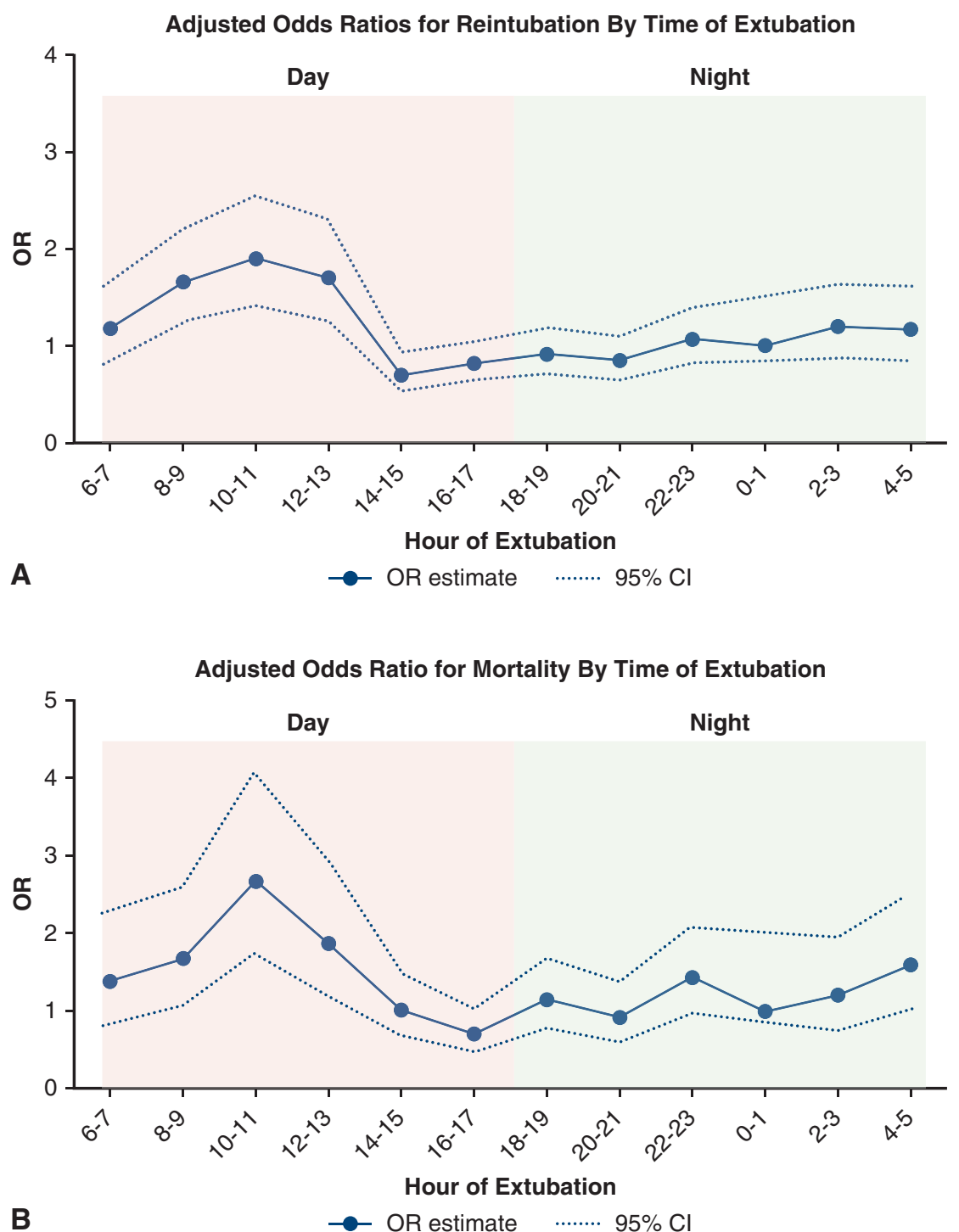

FIGURE 1. A, Adjusted OR for reintubation by time of extubation. Graphical representation of OR for reintubation by time of extubation, controlling for predicted prolonged ventilation and center-specific variation. ORs are shown in solid, and $95 \%$ confidence intervals are dashed boundaries. B, Adjusted OR for mortality by time of extubation. Graphical representation of OR for mortality by time of extubation, controlling for STS PROM and center-specific variation. ORs are shown in solid, and $95 \%$ confidence intervals are shown in dashed boundaries. $O R$, Odds ratio; $C I$, confidence interval. 


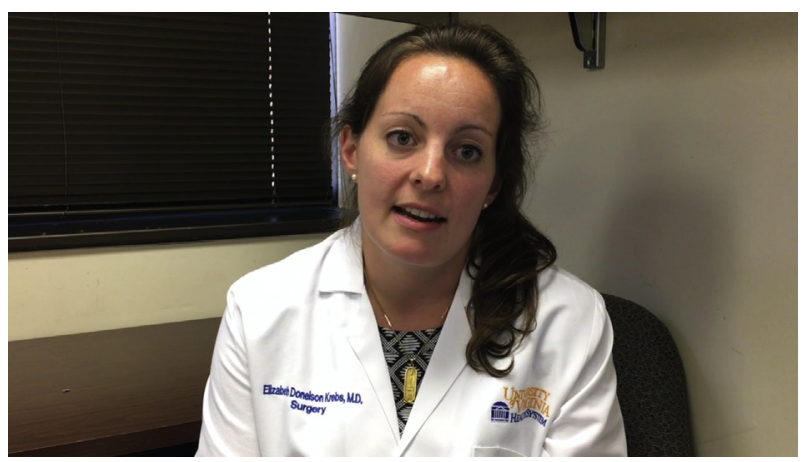

VIDEO 1. The author discusses the article and the importance of this research. Video available at: https://www.jtcvs.org/article/S0022-5223(18) 32926-X/fulltext.

their decreased hours in the ICU. Patients in the night group exhibited equivalent ICU costs and slightly increased total hospital cost on univariate analysis, with no difference in cost after risk adjustment. A cost analysis of varying ICU practice patterns was outside the scope of this study and not possible because of the deinstitutionalized nature of the data, but provides an interesting area for future investigation.

Our results provide guidance for clinical decision making and quality metric reporting. Patients extubated overnight exhibited equivalent rates of reintubation, mortality, and morbidity, suggesting that extubation during night hours does not convey additional risk. Because shorter ventilation times have been associated with improved outcomes, patients who meet clinical parameters for extubation overnight may benefit from extubation at that time, rather than waiting until morning. ${ }^{1,2,6}$ Furthermore, in combination with existing evidence that around the clock intensivist coverage improves outcomes in cardiac surgery patients, these results suggest that continuation of daytime critical care practices to overnight hours is beneficial in these patients. ${ }^{15,16}$ These findings are also important for quality metric reporting, because prolonged mechanical ventilation ( $>24$ hours) is currently included as a major morbidity in STS quality reporting, motivating institutions to extubate patients earlier and overnight. ${ }^{10,12}$ Our results are reassuring in that extubating patients overnight to meet quality metric "deadlines" does not appear to add undue risk. Finally, the observation that patients undergoing routine cardiac surgery exhibit different outcomes than mixed or medical ICU patients highlights the importance of cardiac surgeryspecific critical care practices, as well as continued research into ICU outcomes in these patients.

\section{Study Limitations}

There are several limitations to this investigation. First, the study is retrospective in nature and subject to inherent selection bias. Although risk adjustment did control for known preoperative risk factors, all factors could not be considered and causality cannot be demonstrated retrospectively. It is also possible that centers were more likely to list higher-risk cases earlier in the day, with lower-risk patients listed in the afternoon and subsequently extubated overnight. Despite risk adjustment, confounding due to patient selection may have masked a small detrimental effect of overnight extubation. Second, we were unable to specifically control for intensivist coverage at night because the VCSQI data are deidentified from their institution, and many institutions varied their ICU coverage patterns during the study period. However, we were able to control for center-specific variability using hierarchical modeling methods, thus controlling for institutional ICU practice patterns. Finally, although not necessarily a limitation, it should be noted that the study was limited to patients undergoing CABG or valve surgery and patients who were extubated within 24 hours of surgery. These patients were intentionally selected to represent common cardiac surgery operations, excluding those with complex operations (including complex aortic repairs, ventricular assist device placement, and heart transplants) and with protracted ventilator course. Therefore, the results may not be translatable to these high-risk populations.

\section{CONCLUSIONS}

Half of patients undergoing routine cardiac surgery are extubated overnight, with no increase in risk of reintubation, morbidity, or mortality. These findings contrast with studies in a mixed ICU population, demonstrating that overnight extubation in patients undergoing cardiac surgery is safe. Subgroup analysis shows that extubation after midnight tends to occur in a patient cohort with higher preoperative risk profiles. These patients have a higher than expected rate of composite morbidity-mortality, but extubation-related metrics remain excellent. These results indicate that in the appropriate clinical setting, patients undergoing cardiac surgery may be safely extubated overnight.

\section{Webcast}

You can watch a Webcast of this AATS meeting presentation by going to: https://aats.blob.core.windows.net/ media/18Apr30/28DE\%20Perioperative\%20Care/S73_7_ webcast_041212776.mp4.

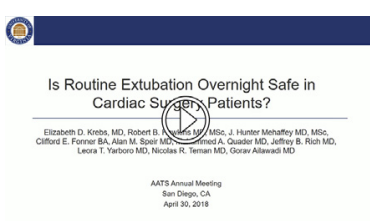




\section{Conflict of Interest Statement}

G.A. is a consultant for Abbott, Medtronic, Edwards Lifesciences, and Cephea Valve Technologies. All other authors have nothing to disclose with regard to commercial support.

\section{References}

1. Cheng DC, Karski J, Peniston C, Asokumar B, Raveendran G, Carroll J, et al. Morbidity outcome in early versus conventional tracheal extubation after coronary artery bypass grafting: a prospective randomized controlled trial. $J$ Thorac Cardiovasc Surg. 1996;112:755-64.

2. Cheng DC, Karski J, Peniston C, Raveendran G, Asokumar B, Carroll J, et al. Early tracheal extubation after coronary artery bypass graft surgery reduces costs and improves resource use. A prospective, randomized, controlled trial. Anesthesiology. 1996;85:1300-10.

3. Camp S, Stamou S, Stiegel R, Reames M, Skipper E, Madjarov J, et al. Can timing of tracheal extubation predict improved outcomes after cardiac surgery? HSR Proc Intensive Care Cardiovasc Anesth. 2009;1:39.

4. Cohen AJ, Katz MG, Frenkel G, Medalion B, Geva D, Schachner A. Morbid results of prolonged intubation after coronary artery bypass surgery. Chest. 2000; 118:1724-31

5. Bouza E, Pérez A, Muñoz P, Perez MJ, Rincón C, Sánchez C, et al. Ventilatorassociated pneumonia after heart surgery: a prospective analysis and the value of surveillance. Crit Care Med. 2003;31:1964-70.

6. LaPar DJ, Gillen JR, Crosby IK, Sawyer RG, Lau CL, Kron IL, et al. Predictors of operative mortality in cardiac surgical patients with prolonged intensive care unit duration. J Am Coll Surg. 2013;216:1116-23.

7. Warltier DC, Myles PS, Daly DJ, Djaiani G, Lee A, Cheng DC. A systematic review of the safety and effectiveness of fast-track cardiac anesthesia. J Am Soc Anesthesiol. 2003;99:982-7.

8. van Mastrigt GA, Maessen JG, Heijmans J, Severens JL, Prins MH. Does fasttrack treatment lead to a decrease of intensive care unit and hospital length of stay in coronary artery bypass patients? A meta-regression of randomized clinical trials. Crit Care Med. 2006;34:1624-34.

9. Richey M, Mann A, He J, Daon E, Wirtz K, Dalton A, et al. Implementation of an early extubation protocol in cardiac surgical patients decreased ventilator time but not intensive care unit or hospital length of stay. J Cardiothorac Vasc Anesth. 2018;32:739-44.

10. Shahian DM, He X, Jacobs JP, Kurlansky PA, Badhwar V, Cleveland JC, et al. The Society of Thoracic Surgeons composite measure of individual surgeon performance for adult cardiac surgery: a report of the Society of Thoracic Surgeons quality measurement task force. Ann Thorac Surg. 2015;100:1315-25.

11. Cove ME, Ying C, Taculod JM, Oon SE, Oh P, Kollengode R, et al. Multidisciplinary extubation protocol in cardiac surgical patients reduces ventilation time and length of stay in the intensive care unit. Ann Thorac Surg. 2016;102:28-34.

12. Shahian DM, Edwards FH, Ferraris VA, Haan CK, Rich JB, Normand S-LT, et al. Quality measurement in adult cardiac surgery: part 1—conceptual framework and measure selection. Ann Thorac Surg. 2007;83:S3-12.

13. Gershengorn HB, Scales DC, Kramer A, Wunsch H. Association between overnight extubations and outcomes in the intensive care unit. JAMA Intern Med. 2016;176:1651-60.

14. Tischenkel BR, Gong MN, Shiloh AL, Pittignano VC, Keschner YG, Glueck JA, et al. Daytime versus nighttime extubations: a comparison of reintubation, length of stay, and mortality. J Intensive Care Med. 2016:31:118-26.

15. Benoit MA, Bagshaw SM, Norris CM, Zibdawi M, Chin WD, Ross DB, et al. Postoperative complications and outcomes associated with a transition to 24/7 intensivist management of cardiac surgery patients. Crit Care Med. 2017;45: 993-1000.

16. Kumar K, Singal R, Manji RA, Zarychanski R, Bell DD, Freed DH, et al. The benefits of 24/7 in-house intensivist coverage for prolonged-stay cardiac surgery patients. J Thorac Cardiovasc Surg. 2014;148:290-7.e296.

17. Speir AM, Kasirajan V, Barnett SD, Fonner E. Additive costs of postoperative complications for isolated coronary artery bypass grafting patients in Virginia. Ann Thorac Surg. 2009;88:40-6.

18. D'Agostino RS, Jacobs JP, Badhwar V, Fernandez FG, Paone G, Wormuth DW, et al. The Society of Thoracic Surgeons adult cardiac surgery database: 2018 update on outcomes and quality. Ann Thorac Surg. 2018;105:15-23.

19. Shahian DM, O'Brien SM, Filardo G, Ferraris VA, Haan CK, Rich JB, et al. The Society of Thoracic Surgeons 2008 cardiac surgery risk models: part 1-coronary artery bypass grafting surgery. Ann Thorac Surg. 2009;88:S2-22.
20. da Silva PSL, Reis ME, Fonseca TSM, Fonseca MCM. Do in-hours or off-hours matter for extubating children in the pediatric intensive care unit? J Crit Care. 2016;36:97-101.

21. Crawford TC, Magruder JT, Grimm JC, Sciortino C, Conte JV, Kim BS, et al. Early extubation: a proposed new metric. Semin Thorac Cardiovasc Surg. 2016;28:290-9.

Key Words: extubation, ventilation, coronary artery bypass grafting, aortic valve replacement, mitral valve replacement

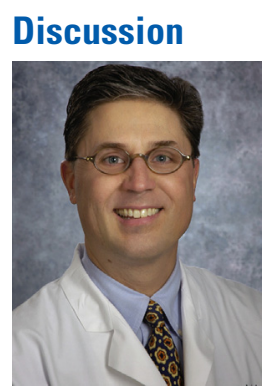

Dr Kevin W. Lobdell (Charlotte, $N C$ ). You reviewed 9 years of work and 39,800 patients who underwent cardiac surgery, and discovered that with standard and satisfactory methodology it is safe to extubate these people overnight without higher rates of reintubation, morbidity, and mortality. Your efforts allude to the STS risk models, and as it might relate to this study, the model for prolonged ventilation, but we need to evolve to where we have a model and some computer decision support that will precisely and personally predict risk of success or failure for individual patients at any point in time.

So, for example, when extubating a patient, we consider host factors such as age, body surface area, creatinine, left ventricular ejection fraction, chronic obstructive pulmonary disease, myocardial infarction, shock, heart rate, respiratory rate, blood pressure, and cardiac index, and then we look at some of the things related to their ventilation and oxygenation. These include, but are not limited to, negative inspiratory force, alveolar oxygen, partial pressure of carbon dioxide, and rapid shallow breathing index. We also consider nonhost factors, such as the time of day, day of week, experience of the care team, and overall acuity in a unit. In addition to macro variables there are micro variables, like biomarkers such as brain natriuretic peptide, lactate, ST2, and even the more recently described damage-associated molecular patterns.

With that in mind, I have questions relating to protocol and compliance for extubation, as well as reintubation and the use of noninvasive positive pressure ventilation. Please share your thoughts on how we evolve in a thoughtful, pragmatic manner so we can precisely and personally predict who is going to be extubated successfully and who needs to be reintubated and when.

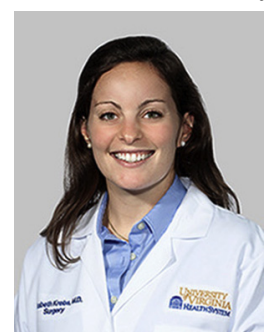

Dr Elizabeth D. Krebs (Charlottesville, $\mathrm{Va}$ ). In terms of protocols and in compliance to protocols for extubation and reintubation, given the deidentified nature of the data, we don't necessarily know who used protocols and who did not, and we do not have a uniform protocol among all the 19 institutions. I do know that at the University of Virginia, we use a combination of extubation protocols and 18-hour per day intensivist coverage in determining when to extubate a patient. 
In terms of new directions for predictive risk scores, as you mentioned, we used the predicted risk of prolonged ventilation in our risk adjustment, because no score exists for reintubation, which is based solely on preoperative factors, including age and demographics.

If we were to move toward a model of predicting minuteto-minute reintubation rates for an individual patient at an individual point in time, a model would also need postoperative factors and operative details, as well as minute-byminute laboratory values and vital signs.

But in this era of big data, I think that's an interesting question and an interesting potential future direction for these predictive risk scores and one that could aid in predicting who is going to be reintubated and certainly optimizing and maintaining low reintubation rates as well as low durations of intubation if we are able to extubate more patients with the help of scores such as that. It's an interesting future direction.

Dr Lobdell. And I think important for a lot of reasons. You could imagine there are some people who walk away and say, hey, what we learned is it's safe to extubate. That's true from what you have studied, but it doesn't tell you anything about one patient or any one institution. So that's why I asked those questions, and I kind of asked in a leading way of what do we do to augment those models.

Dr Krebs. Going along with your point about the safety issue, it should also be noted that in all the different patients, we intentionally limited our patients to routine operations extubated within 24 hours to model relatively low-risk patients. So the data most directly apply to those patients as well.

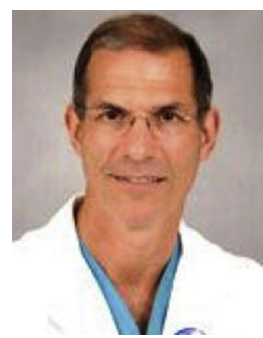

Dr Glenn J. Whitman (Baltimore, $M d)$. Excellent work, but I think this furthers our efforts as ICU directors to encourage extubation overnight when the staff is low, when the nurses are younger, and such, all the barriers we see. The thing that came to mind to me when you are comparing these 2 groups is, as a cardiac surgeon, oftentimes you might do the quicker procedure, safer in patients with less chronic obstructive pulmonary disease, who are less obese, less likely to bleed, and less on Plavix. So at night, it's the night extubation case that might be a bit harder. It's just my gut. I am not sure if you were able to tease that difference out between those 2 groups; it's such a large group, but I would be interested if you agree with that at all.

Dr Krebs. In terms of rates of comorbidities and preoperative risk scores, we actually saw higher-risk scores in the overnight group. I'm not entirely sure why given what you said we might expect that some institutions would put the more difficult patients or the sicker patients earlier.

Dr Whitman. No, the opposite, because I want to make sure I get to the second case.

Dr Krebs. I see what you are saying. So that would indeed support exactly what we saw.

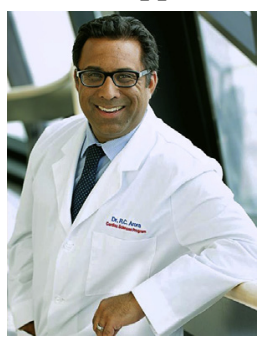

Dr Rakesh Arora (Winnepeg, Canada). To follow up on Dr Lobdell's question, you may not have granular data per patient, but do you know per institution who actually has a safety checklist and extubation protocol, and when it's driven by Advance Care Practitioners versus Medical Doctors? As per the last presentation, what is the overnight staffing in those units that participated in the study?

Dr Krebs. We don't have the exact data for every institution, and the institutions are blinded in our database, so we can't compare them directly. But I do know there is a broad variety and that some have extubation protocols that are almost entirely driven by nurse practitioners and physician assistants; some have largely academic, resident-driven practice patterns, and some have 24/7 intensivist coverage. So it does vary widely, but unfortunately we don't have the exact ability to link those practice patterns to the institutions.

I don't have the exact numbers for the relevant percentages, but that is an interesting question that we could obtain for revisions in our article. 
TABLE E1. Full regression models for risk-adjusted effect of extubation overnight (18:00-06:00) on outcomes

\begin{tabular}{|c|c|c|c|}
\hline Variable & & & \\
\hline \multicolumn{4}{|l|}{ Outcome $=$ Reintubation } \\
\hline C statistic $=0.695$ & OR & $95 \%$ CI & $P$ value \\
\hline Overnight extubation & 0.937 & $0.840-1.046$ & .245 \\
\hline PPV & 1.042 & $1.039-1.046$ & $<.001$ \\
\hline \multicolumn{4}{|c|}{ Outcome $=$ operative mortality } \\
\hline \multicolumn{4}{|l|}{ C statistic $=0.753$} \\
\hline Overnight extubation & 1.013 & $0.865-1.188$ & .871 \\
\hline PROM & 1.131 & $1.119-1.144$ & $<.001$ \\
\hline \multicolumn{4}{|c|}{ Outcome $=$ morbidity or mortality } \\
\hline \multicolumn{4}{|l|}{ C statistic $=0.691$} \\
\hline Overnight extubation & 0.95 & $0.886-1.029$ & .225 \\
\hline PROMM & 1.045 & $1.043-1.048$ & $<.001$ \\
\hline \multicolumn{4}{|c|}{ Outcome $=$ ICU length of stay } \\
\hline Overnight extubation & -4.509 & -6.238 to -2.980 & $<.001$ \\
\hline Predicted long stay & 2.670 & $2.56-2.79$ & $<.001$ \\
\hline \multicolumn{4}{|c|}{ Outcome $=$ postsurgery length of stay } \\
\hline Overnight extubation & -0.020 & -0.123 to -0.83 & .707 \\
\hline Predicted long stay & 0.217 & $0.211-0.224$ & $<.001$ \\
\hline \multicolumn{4}{|c|}{ Outcome $=$ total hospital cost } \\
\hline Overnight extubation & $-\$ 144$ & $-\$ 372-\$ 660$ & .585 \\
\hline PROMM & 792.62 & $770.64-814.59$ & $<.001$ \\
\hline
\end{tabular}

TABLE E2. Full regression models for risk-adjusted effect of extubation between 18:00 and 24:00 and extubation between 24:00 and 06:00 on outcomes

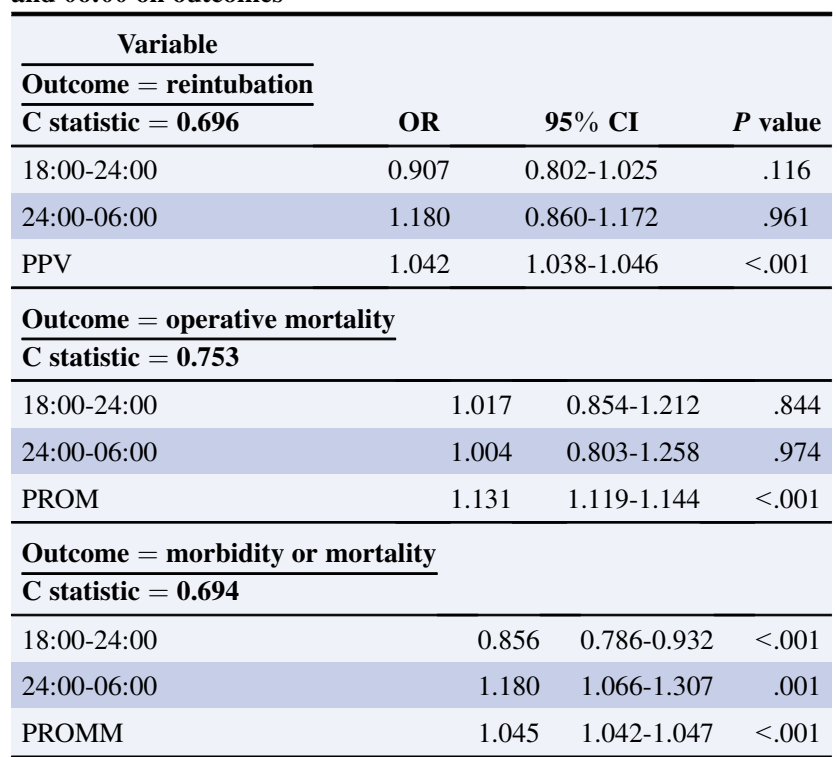

$O R$, Odds ratio; $C I$, confidence interval; $P P V$, predicted prolonged ventilation; $P R O M$, predicted risk of mortality; PROMM, predicted risk of morbidity or mortality.
TABLE E3. Sensitivity analysis risk-adjusted outcomes, summary results

\begin{tabular}{lccr}
\hline \multicolumn{1}{c}{ Logistic regression } & OR & $\mathbf{9 5} \% \mathbf{C I}$ & $\boldsymbol{P}$ value \\
\hline 2-group comparison & & & \\
$\quad$ Reintubation & 0.812 & $0.723-0.912$ & $<.001$ \\
Operative mortality & 0.843 & $0.713-0.998$ & .049 \\
$\quad$ Morbidity or mortality & 0.790 & $0.730-0.856$ & $<.001$ \\
3-group comparison & & & \\
$\quad$ Reintubated during hospital & & & \\
$\quad$ stay & & & \\
18:00-24:00 & 0.827 & $0.729-0.939$ & .003 \\
24:00-06:00 & 0.780 & $0.661-0.919$ & .003 \\
Operative mortality & & & \\
18:00-24:00 & 0.881 & $0.733-1.059$ & .177 \\
24:00-06:00 & 0.768 & $0.604-0.976$ & .031 \\
Morbidity or mortality & & & \\
18:00-24:00 & 0.758 & $0.693-0.828$ & $<.001$ \\
$\quad$ 24:00-06:00 & 0.861 & $0.772-0.961$ & .007 \\
\hline
\end{tabular}

$O R$, Odds ratio; $C I$, confidence interval.

TABLE E4. Full regression models for sensitivity analysis for riskadjusted effect of extubation overnight (18:00-06:00) on outcomes

\begin{tabular}{lcccc}
\hline \multicolumn{1}{c}{ Variable } & & & \\
\cline { 1 - 1 } Outcome $=$ reintubation & & & & \\
\cline { 1 - 1 } C statistic $=\mathbf{0 . 7 0 3}$ & & OR & $\mathbf{9 5} \%$ CI & $\boldsymbol{P}$ value \\
\hline Overnight extubation & 0.812 & $0.723-0.912$ & $<.001$ \\
PPV & 1.036 & $1.032-1.040$ & $<.001$ \\
Extubate within 6 h & 0.614 & $0.542-0.697$ & $<.001$ \\
Bypass time & 1.004 & $1.002-1.005$ & $<.001$ \\
\hline
\end{tabular}

Outcome $=$ operative mortality

C statistic $=0.749$

\begin{tabular}{lllr}
\hline Overnight extubation & 0.843 & $0.713-0.998$ & .049 \\
PROM & 1.120 & $1.108-1.133$ & $<.001$ \\
Extubate within 6 h & 0.629 & $0.524-0.754$ & $<.001$ \\
Bypass Time & 1.006 & $1.004-1.008$ & $<.001$ \\
\hline
\end{tabular}

Outcome $=$ morbidity or mortality

C statistic $=0.712$

\begin{tabular}{llll}
\hline Overnight extubation & 0.790 & $0.730-0.856$ & $<.001$ \\
PROMM & 1.039 & $1.037-1.042$ & $<.001$ \\
Extubate within 6 h & 0.503 & $0.460-0.549$ & $<.001$ \\
Bypass time & 1.003 & $1.002-1.003$ & $<.001$ \\
\hline
\end{tabular}

$O R$, Odds ratio; $C I$, confidence interval; $P P V$, predicted prolonged ventilation $P R O M$, predicted risk of mortality; PROMM, predicted risk of morbidity or mortality. 
TABLE E5. Full regression models for sensitivity analysis for riskadjusted effect of extubation between 18:00 and 24:00 and extubation between 24:00 and 06:00 on outcomes

\begin{tabular}{lcccc}
\hline \multicolumn{1}{c}{ Variable } & & & \\
\cline { 1 - 3 } Outcome $=$ reintubation & & & & \\
\cline { 1 - 2 } C statistic $=\mathbf{0 . 7 0 3}$ & & OR & $\mathbf{9 5}$ CI & $\boldsymbol{P}$ value \\
\hline 18:00-24:00 & 0.827 & $0.729-0.939$ & .003 \\
24:00-06:00 & 0.780 & $0.661-0.919$ & .003 \\
PPV & 1.036 & $1.032-1.040$ & $<.001$ \\
Extubate within 6 h & 0.609 & $0.536-0.693$ & $<.001$ \\
Bypass time & 1.004 & $1.002-1.005$ & $<.001$ \\
\hline
\end{tabular}

Outcome $=$ operative mortality

C statistic $=0.749$

\begin{tabular}{lllr}
\hline 18:00-24:00 & 0.881 & $0.733-1.059$ & .177 \\
24:00-06:00 & 0.768 & $0.604-0.976$ & .031 \\
PROM & 1.121 & $1.108-1.133$ & $<.001$ \\
Extubate within 6 h & 0.615 & $0.511-0.741$ & $<.001$ \\
Bypass time & 1.006 & $1.004-1.008$ & $<.001$ \\
\hline
\end{tabular}

Outcome $=$ morbidity or mortality

C statistic $=0.691$

\begin{tabular}{lllr}
\hline 18:00-24:00 & 0.758 & $0.693-0.828$ & $<.001$ \\
24:00-06:00 & 0.861 & $0.772-0.961$ & .007 \\
PROMM & 1.039 & $1.037-1.042$ & $<.001$ \\
Extubate within 6 h & 0.513 & $0.469-0.561$ & $<.001$ \\
Bypass time & 1.003 & $1.002-1.003$ & $<.001$ \\
\hline
\end{tabular}

$O R$, Odds ratio; $C I$, confidence interval; $P P V$, predicted prolonged ventilation; $P R O M$, predicted risk of mortality; PROMM, predicted risk of morbidity or mortality.

TABLE E6. Regression model for sensitivity analysis for risk-adjusted effect of hour of day on mortality

\begin{tabular}{lccc}
\hline Variable & Estimate & $\mathbf{9 5} \% \mathbf{C I}$ & $\boldsymbol{P}$ value \\
\hline PROM & 1.126 & $1.114-1.138$ & $<.001$ \\
$2-3$ & 1.212 & $0.756-1.943$ & .1233 \\
$4-5$ & 1.602 & $1.02-2.518$ & .002 \\
$6-7$ & 1.387 & $0.832-2.314$ & .1252 \\
$8-9$ & 1.681 & $1.084-2.607$ & $<.001$ \\
$10-11$ & 2.669 & $1.754-4.061$ & $<.001$ \\
\hline $12-13$ & 1.891 & $1.208-2.963$ & .001 \\
$14-15$ & 1.01 & $0.675-1.511$ & $<.001$ \\
\hline $16-17$ & 0.71 & $0.482-1.045$ & $<.001$ \\
$18-19$ & 1.139 & $0.776-1.672$ & $<.001$ \\
\hline $20-21$ & 0.929 & $0.621-1.39$ & $<.001$ \\
$22-23$ & 1.433 & $0.975-2.106$ & .999 \\
\hline
\end{tabular}

c statistic 0.7101 . CI, Confidence interval; PROM, predicted risk of mortality.
TABLE E7. Regression model for sensitivity analysis for risk-adjusted effect of hour of day on need for reintubation

\begin{tabular}{lccc}
\hline Variable & Estimate & $\mathbf{9 5} \% \mathbf{C I}$ & $\boldsymbol{P}$ value \\
\hline PPV & 1.039 & $1.035-1.043$ & $<.001$ \\
$2-3$ & 1.197 & $0.876-1.634$ & .2588 \\
$4-5$ & 1.170 & $0.848-1.634$ & .339 \\
$6-7$ & 1.177 & $0.833-1.664$ & .3552 \\
$8-9$ & 1.656 & $1.243-2.207$ & .0006 \\
$10-11$ & 1.900 & $1.417-2.548$ & $<.001$ \\
$12-13$ & 1.701 & $1.258-2.300$ & .0006 \\
$14-15$ & 0.695 & $0.522-0.926$ & .0129 \\
$16-17$ & 0.814 & $0.635-1.045$ & .1061 \\
$18-19$ & 0.913 & $0.704-1.184$ & .2924 \\
$20-21$ & 0.845 & $0.648-1.102$ & .2142 \\
$22-23$ & 1.069 & $0.822-1.391$ & .617 \\
\hline
\end{tabular}

c statistic $=0.7035$. $C I$, Confidence interval; $P P V$, predicted prolonged ventilation. 